\title{
Feasibility Study of Track and Field Training Informationization in Higher Vocational Colleges
}

\author{
Fan Xiaofan \\ Jilin Technology College of Electronic Information, Jiln, Jilin, China
}

Keywords: Higher vocational college, Track and field training informationization, Feasibility study

\begin{abstract}
The combination of computer and sports has promoted the development of sports, with outstanding performance in sports training. Computers have achieved certain results in the formulation of training plans, control of training load, overall training management, improvement of sports equipment, movement design and performance prediction, making training more scientific. As a major sport, track and field must also take the road of information.
\end{abstract}

\section{Introduction}

With the rapid development of science and technology and modern sport, the computer has been gradually applied to the sports field. Computer science and sports science combined, will greatly improve athletic performance, promote the development of competitive level, speed up the scientific process of sports training. How to put this to the modern high-tech applications in Athletic Training is an important task in front of us every coaches and sports scientists in. To solve this problem, we must be on the current status quo in sports training in computer use to understand, know how to use in training, scientific training, to prepare for the track and field project achieved excellent results in the 21st century.

\section{Problem with Traditional Track and Field Training Method of Vocational Colleges}

At present, we have been following the traditional teaching methods to teachers teachingoriented, teachers simply will train skills and ways to explain the demonstration, the students practice the next class, this approach is not conducive to students to fully grasp the skills of track and field training, students learn boring way, lose interest in track and field training, so we should change the traditional training methods, the use of information technology means to enhance students' learning initiative.

The traditional training methods by the teacher demonstration, explanation, can not master the skills of the details of the operation will be described intuitively clear, students simply by mimicking the teacher's motor skills, the learning process is more blind, for example, a sprinter's practice time, teachers just next to the students repeat the demonstration, and then the students repeated practice alone, leading students cannot correctly understand the starting position, the best angle joints such as jogging adverse effect, if the technical means of information technology, allow students to watch video and other multimedia, can allow students to more intuitively feel sprinter technology, convenient, and efficient completion of training. Information teaching track and field training is still relatively weak, the teachers' usage of information technology is not high, do not pay attention to the specific use of information technology in teaching. While some teachers are constantly improving the application of information technology, but the information itself is not high quality, relevant technology to master the computer operation unskilled, lack of integration and application of information technology training track and field, leading to waste some track and field training resources.

\section{Information Technology Feasibility in Track and Field Training in Vocational Colleges}

Student of track and field action of talks, demonstrations and presentations, sports action can be 
more clear and accurate memory by physical education teachers. But in the process of track and field training, the teacher is difficult to accurately describe the technical movements through language, such as technical details of the training vacated explanation and demonstration, the teacher is difficult to describe the details one by one. If the use of information technology such as multimedia courseware or video applications, these technologies use slow motion mode multi-angle will demonstrate the details to the students, one by one grasp the essentials to explain the action and focuses on helping students understand the action, grasp motion technology, establish clear action appearance.

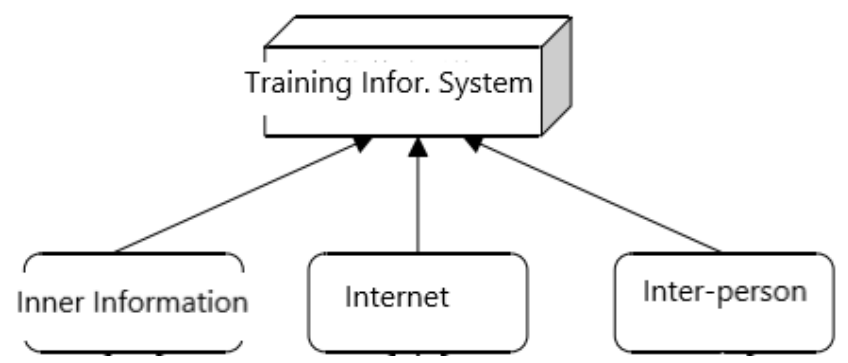

Fig.1 Model Diagram of the Basketball Training Management Information Collection Subsystem

We can through the application of information technology to students track and field training proper planning and coordination, master students of physical health, students clear, scientific training methods; you can also analyze past results of the training track and field events and students, continue to summarize training experience to provide help for future training. In addition, by collecting, sorting information from different track and field training programs, systems analysis training methods for each item, as a means to enhance the training of innovative ideas. In track and field training, if the student's strong interest in training, students will be trained emotions run high, play a good role in training. But students in the learning process, a single class atmosphere, lack of concentration can lead to students so that they explain to the action, analytical understanding is not in place. In track and field training in teaching, if the use of multimedia teaching equipment, multimedia training, to provide a good visual effect, can enrich the training tools, making teaching more clear, lively atmosphere in class, through the creation of scenarios to stimulate student interest in learning and training enthusiasm, promote student training results.

\section{Vocational Colleges Athletic Training Information Technology Methods}

In the information society, teachers should continue to learn how to use information technology to enhance their information literacy. First, teachers should change the traditional method of teaching track and field training, aware of the importance and advantages of information technology education, supporting role of information technology in track and field training, the development of scientific training methods and content for students by means of information; Secondly, regular training school teachers to deal with information technology, improve the level of teachers' use of information technology. The current school of information technology equipment is weak, so the current first need to increase investment in the use of the school's information technology equipment, facilities complete information resource platform for track and field training; secondly, increasing the track and field training classroom for investment in information technology, improve the multi functions of information technology teaching environment, rich in track and field teaching resources through information technology to enhance students' level of training. Third, increase the role of multimedia technology in track and field training, and change the traditional track and field training methods, focusing on students' physical and mental development advice, to combine track and field training methods and the use of multimedia technology, innovative training methods, the use of multi-angle auditory, visual, etc. track and field training teaching. Construction of information technology training system allows a full range of physical education teachers to start teaching the application of information systems training, extensive development and use of information technology training and education systems, development of track and field training of 
teaching resources. First, the development of digital learning resource utilization track and field training, teaching materials increased track and field training, rich track and field classroom; second, the use of information systems, track and field training will be extended to the student's school life to go, open up horizons of students to learn, to improve students utilization of information resources; third, to establish mechanisms for sharing the resources of track and field training, information technology systems as the basis, the shared track and field training, teaching resources, teaching content.

\section{Application of Computer Training Program}

Computer and information processing technologies (Information Processing Technique) referred to IPT, as an important modern training aids in the movement of scientific training and improve training levels are playing an increasingly important role. A high level of training, highly targeted training requirements for athletes, accurate quantitative, rational training rhythm and a large load. The use of computer and information processing technology for the development and management training programs, can realistically state athletic ability and athletic potential for scientific analysis and calculation, more accurate grasp of the various training status and make scientific predictions. The computer system intact standardized training process information in text, data, images, etc., not only can greatly improve the efficiency of coaches, quickly and accurately analyze the statistics of training in a variety of data, can also help coaches avoid Training blindness and randomness, to determine the amount of training provided and load intensity for each training phase, to help coaches develop a scientific training program. High level of competitive sports countries such as the United States, the former East Germany, the UK, Australia, using a computer to develop training programs, control training is very common. In this regard our application was started, try to apply at the national swimming and diving team, gymnastics team, has made significant training benefits. Wang Yongsheng the text "IPT and computer training programs to develop management" discusses the necessity and importance of establishing a computer training program IPT management system and describes how to build the system and the system structure, design principles, work processes, systems features, system operation and control environment.

After the athletes bear a certain degree of exercise load in training would have a corresponding training effect, but to produce good training effect, you must use the appropriate training load. If the load is too small to cause the body's stress response necessary, if an excessive load will produce deterioration reaction. In the past, sports training, coaches with general observations, feelings and subjective experience of qualitative control training, training in the promotion of science today, we have been far can not meet the need to control excessive quantitative, to use more objective parameter control training process. In order to accurately calculate training load, allowing the computer to do the job. Application of the formula $C=M P K$ 'th power ( $K^{\prime}$ is a non-zero real number), $\mathrm{M}$ means the best jumper on its inner training phase given project, $\mathrm{C}$ represents the intensity of a control to calculate training load. Taken in the running project $-1 \leqslant K^{\prime} \leqslant 0 ; 0 \leqslant K^{\prime} \leqslant 1$ take in jumping and throwing projects, through practice that, $400 \mathrm{~m}$ run the following items taken from the $\mathrm{K}^{\prime}=-0.2 ; 800 \mathrm{~m}$ above run items, take $\mathrm{K}$ ' $=-0.25$; taken for jumping and throwing items $\mathrm{K}^{\prime}=0.25$. Load control study of Deng Weiming has written paper, "human movement during the physiological load intensity of Fuzzy computer control”, designed to study the characteristics of human motion, through computer technology and fuzzy control theory, the exploration of the human body during exercise physiology load regulation method for the strength, physical training to improve the efficiency, there is provided a scientific means. Further, research in this area is still promising, for example, in determining the mental load of the athlete, still not possible to describe quantitatively, as can the use of computer processing technology, the operation of the external player through computer processing performance synthesized by psychological oriented athletes, that training will be of great benefit. 
Table 1 Students' Main Views on Multimedia Courseware

\begin{tabular}{|l|l|}
\hline No. & Viewpoints \\
\hline 1 & I feel very fresh and the effect is quite good \\
\hline 2 & The use of courseware can make up for some deficiencies in regular training \\
\hline 3 & The content of the courseware can basically cover the main features of the three projects. It helps a lot \\
\hline 4 & Animations in courseware should also be richer \\
\hline 5 & The use of sound in courseware is not rich enough \\
\hline 6 & Special courseware should be made and applied to training \\
\hline
\end{tabular}

Sports training is an important part of competitive sports, it is to improve athletic ability and athletic performance of athletes, under the guidance of coaches, specialized organizations of the planned sporting activities. Sports training management is the regulation of the entire training process and the various departments involved in the training, coaches, athletes, doctors, researchers, etc. Rigorous and thoughtful management is a prerequisite for the excellent results achieved, in order to better manage, use of computer technology has is the only way, because it is the most fair and impartial. This regard, we should learn to enterprises, the management company of the set, adjust for our athletics training among the benefits of exercise training will be greatly enhanced. Research in this area has to Zheng and other family Gymnastics title, put forward the application to manage the computers in training. Including: 1) Gymnastics action choreography and diagnostics; 2) athletes on their biological storage biochemical indexes analysis; 3) computer-to-guide training; 4) predicted life rhythm player (biological clock); 5) developing recipes; 6) establish business files ; 7) establish databases and other gymnastics. Research on computer management training as well as Sun Xuechuan such as "multi-functional physical training guidance systems --- Computer explore the physical training of athletes," Wang Ye and other "training detection system based on artificial neural network research," Qiu Aihua and other "computer applied research "and so on in sports training management. These are the computer tries to exercise training in management, but as far as I understand the interview, in this regard the concrete application and promotion efforts were not enough, especially in our track and field training is almost no applications, increased research efforts in the future on the one hand to the other aspects should actively promote, so that more sports teams have to use these high-tech research results, and transform it into real benefits.

\section{Conclusion}

Computer and sports combined to achieve a competitive sports information for Scientific Training opened up a new path. Computer Application Research in Sports Training will accomplish much, specific to the track and field training, you can use computer-controlled training ground to manage the entire training process, carried out the Function Evaluation and Training prediction after training. Proposed to speed up the training of personnel in the computer science field training track and field, track and field training to speed up the process of informatization. Recommend coaches in track and field training, more use of software applications have been developed to improve the level of scientific training.

\section{References}

[1] Zhang Xianfeng computer vision and development of track and field training of information technology [J] Xi'an Institute of Physical Education, 2001, 18 (3): 111-113.

[2] Xiaohong Yan, Zhao Gong Track and Field of Training feasibility study of information technology [J]. Information recording material, 2019, 20 (01): 204-205.

[3] Cheng Bing. Of establishment under the college education information background track and field [J]. Stationery and Technology, 2017 (15).

[4] Sun Chaosheng analysis of the impact of multimedia technology on young track and field training [J]. Contemporary Sports Science, 2016, 6 (10): 28-29.

[5] Phoenix super late. Application of Multimedia Technology in Sports Training Colleges and 
Universities [J]. Athletics, 2018.

[6] Bi Yiming China's new era of information technology picture track and field study [J]. Young age: viewpoint, 2017: 67. 